\title{
Supply Chain Model with Stochastic Lead Time, Trade-Credit Financing, and Transportation Discounts
}

\author{
Sung Jun Kim and Biswajit Sarkar \\ Department of Industrial \& Management Engineering, Hanyang University, Ansan, Gyeonggi-do 15588, Republic of Korea \\ Correspondence should be addressed to Biswajit Sarkar; bsbiswajitsarkar@gmail.com
}

Received 26 October 2016; Revised 22 January 2017; Accepted 14 February 2017; Published 18 May 2017

Academic Editor: Mohammad D. Aliyu

Copyright (c) 2017 Sung Jun Kim and Biswajit Sarkar. This is an open access article distributed under the Creative Commons Attribution License, which permits unrestricted use, distribution, and reproduction in any medium, provided the original work is properly cited.

\begin{abstract}
This model extends a two-echelon supply chain model by considering the trade-credit policy, transportations discount to make a coordination mechanism between transportation discounts, trade-credit financing, number of shipments, quality improvement of products, and reduced setup cost in such a way that the total cost of the whole system can be reduced, where the supplier offers trade-credit-period to the buyer. For buyer, the backorder rate is considered as variable. There are two investments to reduce setup cost and to improve quality of products. The model assumes lead time-dependent backorder rate, where the lead time is stochastic in nature. By using the trade-credit policy, the model gives how the credit-period would be determined to achieve the win-win outcome. An iterative algorithm is designed to obtain the global optimum results. Numerical example and sensitivity analysis are given to illustrate the model.
\end{abstract}

\section{Introduction}

Supply chain indicates that the relation among the supply chain players is forever to obtain maximum profit together and individual profit always. The aim of this model is to reduce the total supply chain cost.

Supply chain management (SCM) is the collaboration among suppliers, manufacturers, retailers, and customers. Practically, the aim of the SCM model is to minimize the total cost or to maximize the total profit throughout the channel. In this direction, the idea of integrated vendor-buyer inventory management has been successfully considered since last few decades. In some practical situations, lead time and setup cost can be controlled and reduced in various ways. It is a trend by shortening the lead time and reducing setup cost; the safety stock can be minimized. Thus, the target is always to decrease the stockout loss and improve the service level for the customer as to increase the competitive edge in business within the SCM environment. Thus, the controllable lead time and setup cost reduction are the key concepts to obtain successful business and have attracted extensive research attention [1]. Reduced setup in the basic inventory model was investigated by Porteus [2] which is the key research idea for cost reduction policy in a supply chain.

Ouyang et al. [3] developed a continuous review inventory model for lead time and ordering cost reductions with partial backorders. This model initiated single-vendor multibuyer with ordering cost reduction. In the same direction, Woo et al. [4] and Chang et al. [5] developed several models with cost reduction policies. Zhang et al. [6] developed the integrated vendor-managed inventory (VMI) model for a two-echelon system with ordering cost reduction. Recently, Shin et al. [7] discussed a continuous review inventory model with transportation cost discount and a service level constraint, whereas Huang [8] introduced another new cost reduction policy through order processing. Recently, Sarkar [9] introduced another cost reduction policy with variable demand under imperfect production process. The abovementioned models are several major contributions in this field.

In reality, transportation cost is not always constant. But, many papers used the concept of constant transportation costs. Thus, it is too much important to consider the cost as variable. By using the single-setup-multidelivery (SSMD), 
the number of types of transportation increases always. The primary aim of using SSMD policy is to reduce the holding cost of buyer, but as a result, the transportation cost increases. Therefore, there will be a trade-off between them to control the cost of the whole system. Ganeshan [10] developed a model for managing supply chain inventory, with multiretailer, single-warehouse, and multisupplier. Recently, Sarkar et al. [11, 12] developed two SCM models with constant and variable transportation costs.

Nowadays transportation mode selection with positive manufacturing lead time is more effective in SCM system [13]. Ertogral et al. [14] developed a vendor-buyer supply chain model for production and shipment issues with transportation cost. Kang and Kim [15] discussed a coordination of inventory holding and transportation management in a two-echelon supply chain model. Chung [16] proposed an integrated-inventory model with transportation cost and two-level trade-credit policy.

In real life situation, everybody prefers the best quality of products with the cheapest price. As a result, all industries have to make good quality products with at least cheaper price. That is why, in many cases, some investment can be done to reduce the setup cost and improve the quality of products. In this direction, Ouyang et al. [17] developed an integrated-inventory model with quality improvement, setup cost reduction, and stochastic lead time in an imperfect production process. Basically, they used the concept of Porteus [2] regarding the investment to reduce setup cost and improve the product's quality. They simultaneously optimized lot size, quality improvement parameter, setup cost, safety stock, and lead time to obtain the minimum cost of the integrated model. Sarkar and Moon [18] extended Ouyang et al.s [17] model with variable backorder rate. Yoo et al. [19] introduced inspection process with commercial return and rework during imperfect production for quality investment and quality cost analyses.

In this highly competitive business environment, companies always desire for trade-credit policy for the entire customers. Thus, trade-credit plays an important role in modern business system. Vendors offer trade-credit-period to buyers to encourage sales, promote market shares, and reduce onhand stock. Goyal [20] proposed an economic order quantity model under conditions of permissible delay-in-payments. Aggarwal and Jaggi [21] discussed about ordering policies of deteriorating items under permissible delay-in-payments. Jamal et al. [22] extended the permissible delay-in-payments concepts with allowable shortage and deterioration. Teng [23] discussed an economic order quantity under the conditions of permissible delay-in-payments. Chang [24] wrote a note on permissible delay-in-payments for $(Q, r)$ inventory systems with ordering cost reduction.

Jaber and Osman [25] explained about the coordination of delay-in-payments and profit sharing in a two-echelon supply chain model. Luo [26] examined a buyer-vendor integrated-inventory model with credit-period incentives. Huang [8] proposed an integrated-inventory model under the conditions of order processing cost reduction and permissible delay-in-payments. Sarkar et al. [27] extended an integratedinventory model with variable lead time, defective units, and delay-in-payments. They assumed stochastic lead time in combination with delay-in-payments to reduce total cost of the system. Recently, Sarkar [28] discussed some concept of discount policies from vendor to buyer with variable backorder for buyer and multi-inspection for vendor by considering the fixed lifetime constrains of products. This model emphasized a coordination policy within the supply chain by some special discounts if the buyer agrees to buy some order quantities which are decided by vendor.

In some inventory system, such as fashionable items, the length of the waiting time for the next replenishment would determine whether the backorder is accepted or not. Therefore, backorder rate is variable and dependent on the waiting time for the next replenishment [29]. Pan et al. [30] optimized an inventory model with reorder point, variable lead time, and backorder discount considerations. Pan and Hsiao [31] formulated an integrated-inventory model with controllable lead time and backorder discount considerations. Lee et al. [32] developed a computational algorithmic procedure for optimal inventory policy involving ordering cost reduction and backorder discounts when the lead time demand is controllable. Lo et al. [33] introduced lead time and safety factor in mixed inventory models with backorder discounts. Lin [34] discussed an integrated vendor-buyer inventory model with a backorder price-discount and an effective investment to reduce ordering cost. Huang [8] designed a simple and an efficient algorithm involving ordering cost reduction and backorder price-discount on inventory system under variable lead time.

1.1. Problem Description. This paper illustrates a channel coordination mechanism between transportation discounts, trade-credit financing, number of shipments, quality improvement of products, and reduced setup cost in a twoechelon supply chain model. Table 1 shows the distinction between existing model and this model. The work is different from $[18,35]$ for the purpose of transportation discounts and trade-credit financing. It is differing from [36] from transportation discount and setup cost reduction and quality improvement of products. It is totally differing from [37] as it is a supply chain model and [37] is a basic EPQ model. To show this all, we have added Table 1 for the same. The aim of this model is to minimize the total cost throughout the supply chain network under single-supplier and single-buyer for a single type of product and single-setup-multidelivery (SSMD) policy. The supplier offers trade-credit-period to the buyer and the buyer uses the delay time to increase his/her profit. A continuous review inventory model is considered for both supplier and buyer. For buyer, the backorder rate is considered as variable. An investment is used to reduce setup cost and another investment is used to improve the quality of products. To reduce the total supply chain cost, the model assumes lead time-dependent backorder rate, where the lead time is stochastic in nature. By using the trade-credit policy, the model gives how the credit-period would be benefited for the whole system. The paper is designed as follows: Section 2 
introduces the mathematical model. In Section 3, numerical example is given. Section 4 gives the conclusions of the model.

\section{Mathematical Model}

2.1. Notation. The following notation are used to develop the model.

(i) Decision Variables

Q: buyer's order quantity (units).

$A_{s}$ : supplier's setup cost per setup (\$/setup).

$L$ : length of lead time in unit time (days).

$\theta$ : probability of the production process which may go to out-of-control state during producing a lot.

$k$ : safety factor for reorder point.

$m$ : number of lots delivered from the supplier to the buyer in one production cycle, a positive integer.

\section{(ii) Parameters}

$A_{b}$ : buyer's ordering cost per order (\$/order).

$D$ : average demand per unit time (units/year).

$h_{b}$ : buyer's inventory holding cost per unit per unit time (\$/unit/year).

$h_{s}$ : supplier's inventory holding cost per unit per unit time (\$/unit/year).

$\pi$ : stockout cost per unit short (\$/unit short).

$r$ : reorder point (units).

$\sigma$ : standard deviation of the lead time demand.

$\theta_{0}$ : initial probability of the production process which may go to out-of-control state during producing a lot.

$\alpha$ : annual fractional cost of capital investment to reduce setup cost (\$/year).

$I(A, \theta)$ : total investment for setup cost reduction from $A_{0}$ to $A$ and quality improvement from $\theta_{0}$ to $\theta$.

$L_{i}$ : length of the lead time components for $i=$ $1,2, \ldots, n$.

$c_{i}$ : crashing cost per unit time $L_{i}$ (\$/unit time).

$X$ : lead time demand which has distribution function $F$ (units).

$E(X)$ : mathematical expectation of $X$.

$z^{+}: \max \{z, 0\}$, where $z$ is any random variable.

$E(X-r)^{+}$: expected shortage quantity at the end of the cycle.

$P$ : production rate (unit/unit time).

$i_{b}$ : buyer's interest or opportunity cost in annual percentage.

$i_{s}$ : supplier's interest or opportunity cost in annual percentage.

$t c_{i}$ : transportation cost for $i$ th unit, $i=1,2, \ldots, n$ (\$/unit).
$N$ : length of credit-period (unit time).

$s$ : rework cost per unit defective item (\$/unit defective item).

$p c$ : purchasing cost per unit (\$/unit).

2.2. Assumptions. The following assumptions are considered to formulate this model. These assumptions are mainly adopted from Sarkar and Moon [18] and Arkan and Hejazi [36].

(i) The study considers a supply chain model for a single type of products with the single-setup-multidelivery (SSMD) policy and controllable lead time.

(ii) The lead time $L$ has $n$ mutually independent components. The $i$ th component has a normal duration $T_{i}$ and the minimum duration $t_{i}$ with crashing cost per unit time $c_{i}$ with $c_{1} \leq c_{2} \leq c_{3} \leq \cdots \leq c_{n}$. The lead time demand $X$ follows a normal distribution with mean $D L$ and standard deviation $\sigma \sqrt{L}$ (Ouyang et al. [35]).

(iii) Let $L_{0}=\sum_{j=1}^{n} T_{j}$ and $L_{i}$ be the length of the lead time with components $1,2,3, \ldots, i$ crashed to their minimum duration. Then, $L_{i}$ can be considered as $L_{i}=L_{0}-\sum_{j=1}^{i}\left(T_{j}-t_{j}\right)$ and the lead time crashing cost per cycle $R(L)$ can be expressed as $R(L)=c_{i}\left(L_{i}\right.$ $L)+\sum_{j=1}^{i-1} c_{j}\left(T_{j}-t_{j}\right)$ for $=1,2, \ldots, n$ (see for reference Ouyang et al. [35]).

(iv) This model considers the variable backorder rate $\beta$ with respect to lead time (Sarkar and Moon [18]).

(v) Logarithmic expressions are assumed for both quality improvement and setup cost reduction (Porteus, [37]).

(vi) The trade-credit financing is considered to make it a cost-reduced supply chain.

(vii) The supplier provides a transportation cost discount, when the buyer places the order of $Q$ units.

2.3. Model Formulation. The model considers the singlesetup-multidelivery (SSMD) policy in a single-supplier single-buyer supply chain model. If the buyer orders quantity $Q$ when the on-hand inventory reaches the reorder point $r$, that is, it considers $(Q, r)$ continuous review inventory model, to save holding cost of the buyer, the supplier produces $m Q$ quantities, which will be delivered to the buyer $m$ times in one production cycle. Thus, the expected cycle length for the supplier is $m Q / D$ and for the buyer is $Q / D$, respectively. Therefore, the ordering cost per unit time for the buyer is $A_{b} D / Q$.

If the inventory level reaches the reorder point $r$, where $r=D L+k \sigma \sqrt{L}, D L=$ the expected demand during the lead time, $k \sigma \sqrt{L}=$ safety stock (SS), and $k=$ safety factor, the buyer places an order of quantity $Q$. Thus, before receiving an order, the inventory is $r-D L$ and after receiving the order, the inventory is $Q+(r-D L)$. Hence, the average inventory over a cycle can be written as $Q / 2+r-D L$. Therefore, the holding cost per unit per unit time of the buyer is $h_{b}(Q / 2+r-D L)$. 
TABLE 1: Distinction between previous and this model.

\begin{tabular}{|c|c|c|c|c|c|c|c|}
\hline Author(s) & $\begin{array}{c}\text { Supply chain } \\
\text { model }\end{array}$ & $\begin{array}{c}\text { Variable lead } \\
\text { time }\end{array}$ & $\begin{array}{c}\text { Variable } \\
\text { backorder }\end{array}$ & $\begin{array}{l}\text { Setup cost } \\
\text { reduction }\end{array}$ & $\begin{array}{c}\text { Quality } \\
\text { improvement }\end{array}$ & $\begin{array}{c}\text { Transportation } \\
\text { discounts }\end{array}$ & $\begin{array}{c}\text { Trade-credit } \\
\text { financing }\end{array}$ \\
\hline Porteus, 1986 & & & & $\sqrt{ }$ & $\sqrt{ }$ & & \\
\hline Ouyang et al., 1996 & & $\sqrt{ }$ & & & & & \\
\hline Moon and Choi, 1998 & & $\sqrt{ }$ & & & & & \\
\hline Hariga and Ben-Daya, 1999 & & $\sqrt{ }$ & & & & & \\
\hline Ouyang and Chuang, 2001 & & $\sqrt{ }$ & $\sqrt{ }$ & & & & \\
\hline Ouyang et al., 2002 & & $\sqrt{ }$ & & $\sqrt{ }$ & $\sqrt{ }$ & & \\
\hline Lee, 2005 & & $\sqrt{ }$ & $\sqrt{ }$ & & & & \\
\hline Lin, 2008 & & $\sqrt{ }$ & $\sqrt{ }$ & & & & \\
\hline Sarkar and Majumder, 2013 & $\sqrt{ }$ & $\sqrt{ }$ & & $\sqrt{ }$ & & & \\
\hline Sarkar and Moon, 2014 & & $\sqrt{ }$ & $\sqrt{ }$ & $\sqrt{ }$ & $\sqrt{ }$ & & \\
\hline Sarkar et al., 2014 & $\sqrt{ }$ & $\sqrt{ }$ & & & & & $\sqrt{ }$ \\
\hline Sarkar et al., 2015 & $\sqrt{ }$ & & & $\sqrt{ }$ & & & \\
\hline This research & $\sqrt{ }$ & $\sqrt{ }$ & $\sqrt{ }$ & $\sqrt{ }$ & $\sqrt{ }$ & $\sqrt{ }$ & $\sqrt{ }$ \\
\hline
\end{tabular}

The model assumes that the lead time demand $X$ follows a normal distribution with mean $D L$, standard deviation $\sigma \sqrt{L}$, and safety factor $k$. Thus, the reorder point $r=D L+k \sigma \sqrt{L}$. If $X<r$, then shortage occurs. Hence, the expected shortage at the end of the cycle is $E(X-r)^{+}$, and then expected shortage cost per unit time is $(\pi D / Q) E(X-r)^{+}$.

The concept of Ouyang et al. [35] for lead time crashing cost is used in this model. The lead time $L$ has $n$ mutually independent components. The $i$ th component has a normal duration $T_{i}$ and the minimum duration $t_{i}$ with crashing cost per unit time $c_{i}$ with $c_{1} \leq c_{2} \leq c_{3} \leq \cdots \leq c_{n}$. Let $L_{0}=\sum_{j=1}^{n} T_{j}$ and $L_{i}$ be the length of the lead time with components $1,2,3, \ldots, i$ crashed to their minimum duration. Then, $L_{i}$ can be written as $L_{i}=L_{0}-\sum_{j=1}^{i}\left(T_{j}-t_{j}\right)$ and the lead time crashing cost per cycle $R(L)$ can be expressed as $R(L)=c_{i}\left(L_{i}-L\right)+\sum_{j=1}^{i-1} c_{i}\left(T_{i}-t_{j}\right)$ for $i=1,2, \ldots, n$. Thus, the lead time crashing cost per unit time is $(D / Q) R(L)$. Therefore, the total expected cost per unit time to the buyer can be expressed as follows:

$$
\begin{aligned}
T C_{b}(Q, L)= & \frac{A_{b} D}{Q}+h_{b}\left(\frac{Q}{2}+r-D L\right) \\
& +\frac{\pi D}{Q} E(X-r)^{+}+\frac{D}{Q} R(L) .
\end{aligned}
$$

In reality, the fixed or constant backorder rate is very rare and it is found only in case of life saving drugs, costly products, or others. But for any low-cost products, it is generally variable. Thus, based on lead time of this model, we use the concept of Sarkar and Moon [18] for the backorder rate as a function of the lead time as follows:

$$
\beta=\frac{1}{1+\rho \sigma \sqrt{L} \psi(k)},
$$

$\rho$ being a constant, $0<\rho<\infty$.
Thus, total expected cost per unit time for the buyer, considering the partial backorder, can be expressed as

$$
\begin{aligned}
T C_{b}(Q, L, k) & \\
= & \frac{A_{b} D}{Q}+h_{b}\left(\frac{Q}{2}+r-D L+(1-\beta) E(X-r)^{+}\right) \\
& +\frac{\left[\pi+\pi_{0}(1-\beta)\right] D}{Q} E(X-r)^{+}+\frac{D}{Q} R(L) .
\end{aligned}
$$

Using the above, the expected shortage at the end of the cycle can be expressed as

$$
\begin{aligned}
E(X-r)^{+} & =\int_{r}^{\infty}(X-r) d F(x) \\
& =\sigma \sqrt{L}\{\phi(k)-k(1-\Phi(k))\} \\
& =\sigma \sqrt{L} \psi(k),
\end{aligned}
$$

where $\psi(k)=\phi(k)-k(1-\Phi(k)), \phi(k)$ and $\Phi(k)$ are the standard normal distribution function and the cumulative distribution function of the normal distribution, respectively. Thus, the safety factor $k$ can be treated as a decision variable instead of $r$. Therefore, total expected cost per unit time for the buyer considering the partial backorder can be written as

$$
\begin{gathered}
T C_{b}(Q, L, k)=\frac{A_{b} D}{Q}+h_{b}\left(\frac{Q}{2}+k \sigma \sqrt{L}\right)+\sigma \sqrt{L} \psi(k) \\
.\left[h_{b} \frac{\rho \sigma \sqrt{L} \psi(k)}{1+\rho \sigma \sqrt{L} \psi(k)}\right. \\
\left.+\frac{D}{Q}\left(\pi+\pi_{0} \frac{\rho \sigma \sqrt{L} \psi(k)}{1+\rho \sigma \sqrt{L} \psi(k)}\right)\right]+\frac{D}{Q} R(L) .
\end{gathered}
$$

In this model, under the SSMD policy, the cycle length for supplier is $m Q / D$. Thus, the setup cost per unit time for the supplier is $A_{s} D / m Q$ (see for instance Figure 1). The average 


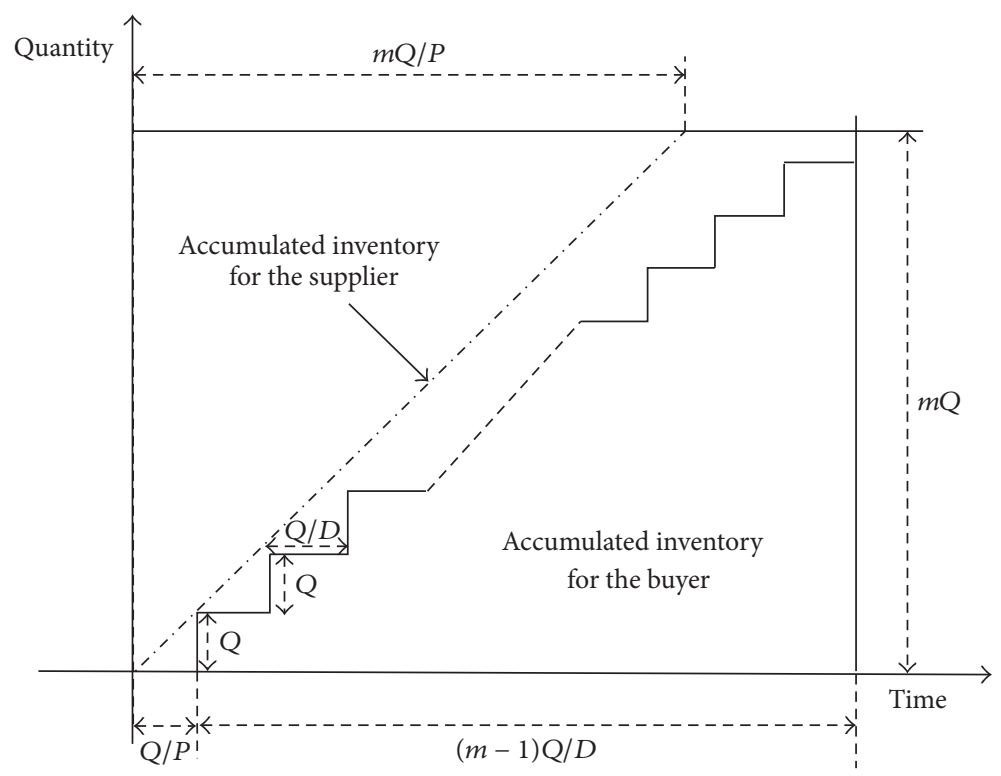

FIGURE 1: Inventory pattern under the SSMD policy (see for reference Ouyang et al. [38]).

inventory of the supplier can be written as $[\{m Q(Q / P+$ $\left.(m-1)(Q / D))-m^{2} Q^{2} / 2 P\right\}-\left\{\left(Q^{2} / D\right)(1+2+\cdots+(m-\right.$ $1))\}](D / m Q)=(Q / 2)[m(1-D / P)-1+2 D / P]$. Hence, the holding cost per unit per unit time for the supplier becomes $h_{s}(D / 2)[m(1-D / P)-1+2 D / P]$.

In this model, there are two investments to reduce the total supply chain cost to make the supply chain more profitable. An investment is used to improve the quality of products and another investment is used to reduce setup cost. We consider the concept of Porteus [37] for quality improvement $I_{\theta}(\theta)=b \ln \left(\theta_{0} / \theta\right)$ for $0<\theta \leq \theta_{0}$ and for setup cost reduction $I_{A}(A)=B \ln \left(A_{0} / A\right)$ for $0<A \leq A_{0}$. Hence, the supplier's the total investment for quality improvement and setup cost reduction becomes as follows:

$$
I(A, \theta)=I_{\theta}(\theta)+I_{A}(A)=G-b \ln \theta-B \ln A,
$$

where $G=b \ln \left(\theta_{0}\right)+B \ln \left(A_{0}\right)$.

Using the concept of defective items, the expected annual total cost is

$$
T C_{s}(m, Q, r, L)=C(m, Q, r, L)+\frac{s D m Q \theta}{2} .
$$

Therefore, the total expected cost per unit time for supplier can be expressed as follows:

$$
\begin{aligned}
T_{s}\left(Q, \theta, A_{s}, m\right)= & \frac{A_{s} D}{m Q} \\
& +h_{s} \frac{D}{2}\left[m\left(1-\frac{D}{P}\right)-1+\frac{2 D}{P}\right] \\
& +\alpha\left(G-b \ln \theta-B \ln A_{s}\right) \\
& +\frac{s D m Q \theta}{2}
\end{aligned}
$$

for $0<\theta \leq \theta_{0}$ and $0<A \leq A_{0}$.
To make the profitable supply chain, an attempt of tradecredit policy is used. By using the trade-credit policy, buyer saves his/her total interest during the credit-period and the supplier lost opportunity cost. We define the trade-credit cost for buyer offered by the supplier as follows:

$$
\begin{gathered}
\frac{p c(Q-D N)^{2} i_{s}}{2 D}-\frac{D^{2} p c N^{2} i_{b}}{2 D} \\
-\frac{p c N i_{b}}{D} \frac{\sigma \sqrt{L} \psi(k)}{1+\rho \sigma \sqrt{L} \psi(k)} .
\end{gathered}
$$

Nowadays, for highly competitive business market, transportation cost is a major issue of the total operational cost in SCM. For appropriate incorporation of transportation cost into the total annual cost function, it should identify the exact transportation cost which relates the reality. In many SCM models, the transportation cost is only considered implicitly as a part of fixed setup or ordering cost and thus, it is assumed to be the independent of the size of the shipment. In this section, we address the case, where the transportation cost is explicitly considered in the model. The structure of all-unitdiscount transportation cost is adopted, which is similar to Ertogral et al. [14] (see Table 2 for it).

Another attempt of transportation cost discount is considered to make a SCM forever. For selling large quantities, the supplier offers a transportation cost discount to the buyer. In this model, the transportation cost is dependent on $Q$. We consider that the supplier offers the discount once the buyer places the order $Q$ units. Thus, the buyer orders quantity $Q$ for the transportation cost discounts from the supplier. Besides, the supplier carries quantity $Y$ instead of $Q$ due to various reasons. However, this imperfect quantity $Y$ does not affect the transportation cost discount condition. For a given shipment of lot size $Q \in\left[M_{i}, M_{i+1}\right)$, transportation cost per unit time is equal to $C_{i} Q /(Q / D)=C_{i} D$, which can be found 
TABLE 2: Structure of all-unit-discount transportation cost.

\begin{tabular}{|c|c|}
\hline Range & Unit transportation cost \\
\hline $0 \leq Q<M_{1}$ & $C_{0}$ \\
\hline$M_{1} \leq Q<M_{2}$ & $C_{1}$ \\
\hline$M_{2} \leq Q<M_{3}$ & $\mathrm{C}_{2}$ \\
\hline$\vdots$ & $\vdots$ \\
\hline$M_{b-1} \leq Q<M_{b}$ & $C_{b-1}$ \\
\hline$M_{b} \leq Q$ & $>C_{b}$ \\
\hline
\end{tabular}

by dividing the transportation cost per order cycle by the duration of the order cycle. The transportation cost can be represented as

$$
T D(Q)= \begin{cases}C_{0} D, & Q \in\left[0, M_{1}\right), \\ C_{1} D, & Q \in\left[M_{1}, M_{2}\right), \\ C_{2} D, & Q \in\left[M_{2}, M_{3}\right), \\ \vdots & \vdots \\ C_{b} D, & Q \in\left[M_{b}, \infty\right) .\end{cases}
$$

Hence, the expected annual total cost per unit time includes the receiving of uncertain quantity and the transportation cost for the SCM model with partial backorder, setup cost, quality improvement, and trade-credit. Therefore, this problem reduces to

$\min T C_{s c}\left(Q, k, \theta, A_{s}, m, L\right)$

$$
\begin{aligned}
= & \frac{A_{b} D}{Q}+h_{b}\left(\frac{Q}{2}+k \sigma \sqrt{L}\right)+\sigma \sqrt{L} \psi(k)\left[h_{b} \frac{\rho \sigma \sqrt{L} \psi(k)}{1+\rho \sigma \sqrt{L} \psi(k)}+\frac{D}{Q}\left(\pi+\pi_{0} \frac{\rho \sigma \sqrt{L} \psi(k)}{1+\rho \sigma \sqrt{L} \psi(k)}\right)\right] \\
& +\frac{D}{Q}\left[c_{i}\left(L_{i}-L\right)+\sum_{j=1}^{i-1} c_{i}\left(T_{i}-t_{j}\right)\right]-\frac{D^{2} p c N^{2} i_{b}}{2 Q}-\frac{D p c N i_{b}}{Q} \frac{\sigma \sqrt{L} \psi(k)}{1+\rho \sigma \sqrt{L} \psi(k)}+\frac{A_{s} D}{m Q} \\
& +h_{s} \frac{Q}{2}\left[m\left(1-\frac{D}{P}\right)-1+\frac{2 D}{P}\right]+\alpha\left(G-b \ln \theta-B \ln A_{s}\right)+\frac{s D m Q \theta}{2}+\frac{p c(Q-D N)^{2} i_{s}}{2 Q}+T D(Q)
\end{aligned}
$$

subject to $0<\theta \leq \theta_{0}$,

$$
0<A \leq A_{0} .
$$

2.4. Solution Procedure. Now the optimum cost of the whole supply chain model is calculated. To do that optimization, we initially ignore all constraints and calculate all the partial derivatives which are necessary for the optimization; then all restrictions are applied on it. The values of all the partial derivatives are as follows:

$$
\begin{aligned}
& \frac{\partial T C_{s c}}{\partial Q}=\frac{1}{Q^{2}}\left[-A_{b} D-\frac{D \bar{\pi} \xi}{\rho}-D R(L)+\frac{p c i_{b} D^{2} N^{2}}{2}\right. \\
& \left.+\frac{p c i_{b} D N^{2} \xi}{2(1+\xi)}-\frac{p c i_{s} D^{2} N^{2}}{2}-\frac{A_{s} D}{m}\right]+\frac{h_{b}}{2} \\
& \quad+\frac{s D \theta m}{2}+\frac{h_{s}}{2}\left[m\left(1-\frac{D}{P}\right)-1+\frac{2 D}{P}\right]+\frac{p c i_{s}}{2}, \\
& \frac{\partial T C_{s c}}{\partial k}=h_{b} \sigma \sqrt{L}+\sigma \sqrt{L} \xi_{3}\left[\frac{h_{b} \xi}{(1+\xi)}+\frac{D \bar{\pi}}{Q}\right] \\
& +\sigma \sqrt{L}\left[\frac{h_{b} \xi \xi_{3}}{(1+\xi)^{2}}+\frac{D \pi_{0} \xi \xi_{3}}{Q(1+\xi)^{2}}\right]-\frac{D p c N i_{b} \rho \sqrt{L} \xi_{3}}{Q(1+\xi)^{2}},
\end{aligned}
$$

$$
\begin{aligned}
& \frac{\partial T C_{s c}}{\partial \theta}=-\frac{\alpha b}{\theta}+\frac{s D m Q}{2}, \\
& \frac{\partial T C_{s c}}{\partial A_{s}}=\frac{D}{m Q}-\frac{\alpha B}{A_{s}} \\
& \frac{\partial T C_{s c}}{\partial m}=-\frac{A_{s} D}{m^{2} Q}+\frac{h_{s} Q}{2}\left(1-\frac{D}{P}\right)+\frac{s D Q \theta}{2} \\
& \frac{\partial T C_{s c}}{\partial L}=\frac{1}{2} h_{b} k \sigma L^{-1 / 2}-\frac{D}{Q} c_{i}+\left(\frac{h_{b} \xi^{2} L^{-1 / 2}}{\rho}+\frac{D \pi_{0} \xi^{2}}{Q \rho L^{2}}\right. \\
& \left.-\frac{D p c N i_{b} \xi}{2 Q \rho L}\right)-\frac{\xi}{2(1+\xi)^{2}}\left[h_{b} \rho \psi(k)^{2} \sigma^{2}\right. \\
& \left.+\frac{D \pi_{0} \rho \psi(k)^{2} \sigma^{2}}{Q}-\frac{D p c N i_{b} \sigma \psi(k)}{Q}\right],
\end{aligned}
$$

where $\bar{\pi}=\pi+\pi_{0} \xi /\left(1+\xi^{\prime}\right), \xi=\rho \sigma \sqrt{L} \psi(k)$, and $\xi_{3}=$ $\Phi(k)-1$. 
To obtain the global minimum solution of the supply chain model, the following second-order partial derivatives are used to calculate all minors:

$$
\begin{aligned}
& \frac{\partial^{2} T C_{s c}}{\partial Q^{2}}=\frac{2}{Q^{3}}\left[A_{b} D+\frac{D \bar{\pi} \xi}{\rho}+D R(L)-\frac{p c i_{b} D^{2} N^{2}}{2}\right. \\
& \left.-\frac{p c i_{b} D N^{2} \xi}{2(1+\xi)}+\frac{p c i_{s} D^{2} N^{2}}{2}+\frac{A_{s} D}{m}\right], \\
& \frac{\partial^{2} T C_{s c}}{\partial k^{2}}=\sigma \sqrt{L} \varphi(k)\left[\frac{h_{b} \xi}{(1+\xi)}+\frac{D \bar{\pi}}{Q}\right]+\sigma \sqrt{L}(\Phi(k) \\
& \text { - 1) }\left[\frac{h_{b} \rho \sigma \sqrt{L}(\Phi(k)-1)}{(1+\xi)}\right. \\
& \left.-\frac{h_{b} \rho^{2} \sigma^{2} L(\Phi(k)-1) \psi(k)}{(1+\xi)^{2}}\right]+\sigma \sqrt{L}(\Phi(k)-1) \\
& \cdot\left[\left(h_{b} \rho \sigma \sqrt{L}+\frac{D \pi_{0} \sigma \rho \sqrt{L}}{Q}\right)\left(\frac{(\Phi(k)-1)}{(1+\xi)^{2}}\right)\right] \\
& +\sigma \sqrt{L} \psi(k)\left[( h _ { b } \rho \sigma \sqrt { L } + \frac { D \pi _ { 0 } \sigma \rho \sqrt { L } } { Q } ) \left(\frac{\varphi(k)}{(1+\xi)^{2}}\right.\right. \\
& \left.\left.-\frac{2 \rho \sigma \sqrt{L}((\Phi(k)-1))^{2}}{(1+\xi)^{2}}\right)\right]-\frac{D p c N i_{b} \rho \sqrt{L} \varphi(k)}{Q(1+\xi)^{2}} \\
& +\frac{2 D p c N i_{b} \rho^{2} \sigma^{2} L((\Phi(k)-1))^{2}}{Q(1+\xi)^{3}}, \\
& \frac{\partial^{2} T C_{s c}}{\partial \theta^{2}}=\frac{\alpha b}{\theta^{2}}, \\
& \frac{\partial^{2} T C_{s c}}{\partial A_{s}{ }^{2}}=\frac{\alpha B}{A_{s}^{2}}, \\
& \frac{\partial^{2} T C_{s c}}{\partial m^{2}}=\frac{2 A_{s} D}{m^{3} Q},
\end{aligned}
$$

$$
\begin{aligned}
& \frac{\partial^{2} T C_{s c}}{\partial L^{2}}=-\left[\frac{1}{4} h_{b} k \sigma L^{-3 / 2}+\frac{1}{2}\right. \\
& \cdot \frac{\xi^{2}}{L^{5 / 2}(1+\xi)^{3}}\left\{\frac{D p c N i_{b} \sigma \psi(k)}{2 Q}-\frac{h_{b} \xi^{2} L^{-3 / 2}}{\rho}\right. \\
& \left.-\frac{D \pi_{0} \xi^{2} L^{-3 / 2}}{\rho Q}\right\}+\frac{\xi}{2 L\left((1+\xi)^{2}\right)}\left(\frac{2 h_{b} \xi^{2}}{\rho L^{2}}\right. \\
& \left.\left.+\frac{3}{2} \frac{D \pi_{0} \xi^{2}}{\rho Q L^{2}}-\frac{D p c N i_{b}}{2 Q}\left(\frac{\xi+(1+\xi) \rho}{L \rho}\right)\right)\right]
\end{aligned}
$$

where $\bar{\pi}=\pi+\pi_{0} \xi /\left(1+\xi^{\prime}\right), \xi=\rho \sigma \sqrt{L} \psi(k)$, and $\xi_{3}=\Phi(k)-1$.

It is found that $T C_{s c}\left(Q, k, \theta, A_{s}, m, L\right)$ is concave with respect to $L$ as the second-order partial derivative of $T C_{s c}\left(Q, k, \theta, A_{s}, m, L\right)$ with respect to $L$ which is negative as the 2 nd term is very smaller than the 1st term within the parenthesis; that is,

$$
\begin{aligned}
& \frac{\partial^{2} T C_{s c}}{\partial L^{2}}=-\left[\frac{1}{4} h_{b} k \sigma L^{-3 / 2}+\frac{1}{2}\right. \\
& \cdot \frac{\xi^{2}}{L^{5 / 2}(1+\xi)^{3}}\left\{\frac{D p c N i_{b} \sigma \psi(k)}{2 Q}-\frac{h_{b} \xi^{2} L^{-3 / 2}}{\rho}\right. \\
& \left.-\frac{D \pi_{0} \xi^{2} L^{-3 / 2}}{\rho Q}\right\}+\frac{\xi}{2 L\left((1+\xi)^{2}\right)}\left(\frac{2 h_{b} \xi^{2}}{\rho L^{2}}\right. \\
& \left.\left.+\frac{3}{2} \frac{D \pi_{0} \xi^{2}}{\rho Q L^{2}}-\frac{D p c N i_{b}}{2 Q}\left(\frac{\xi+(1+\xi) \rho}{L \rho}\right)\right)\right]<0 .
\end{aligned}
$$

Thus, by taking the values of $Q, k, \theta, A_{s}$, and $m$ as constant, $T C_{s c}\left(\mathrm{Q}, k, \theta, A_{s}, m, L\right)$ is concave with respect to $L$. Hence, for constant values of $Q, k, \theta, A_{s}$, and $m$, the minimum expected cost can be obtained from the end point of $\left[L_{i}, L_{i-1}\right]$. Thus, the optimal values of $Q, k, \theta, A_{s}$, and $m$ can be obtained for given $L \in\left[L_{i}, L_{i-1}\right]$. Therefore, equating other four partial derivatives to zero, we can find the optimum values as

$$
\begin{aligned}
Q & =\sqrt{\frac{\left[A_{b} D+D \bar{\pi} \xi / \rho+D R(L)-p c i_{b} D^{2} N^{2} / 2-p c i_{b} D N^{2} \xi / 2(1+\xi)+p c i_{s} D^{2} N^{2} / 2+A_{s} D / m\right]}{h_{b} / 2+s D \theta m / 2+\left(h_{s} / 2\right)[m(1-D / P)-1+2 D / P]+p c i_{s} / 2}}, \\
\Phi(k) & =1-\frac{(1+\xi)^{2} h_{b} Q}{h_{b} \xi Q(1+\xi)+D \bar{\pi} Q(1+\xi)^{2}+h_{b} \xi Q+D \pi_{0} \xi-D p c N i_{b} \rho}, \\
\theta & =\frac{2 \alpha b}{s D m Q}, \\
A_{s} & =\frac{\alpha B m Q}{D} .
\end{aligned}
$$


Lemma 1. For a given $L \in\left[L_{i}, L_{i-1}\right], T C_{s c}\left(Q, k, \theta, A_{s}, m, L\right)$ has the global minimum solution at the optimal values $\left(Q^{*}, k^{*}, \theta^{*}, A_{s}{ }^{*}\right)$.

Proof. See Appendix.

It is a nonlinear program. Thus, the following algorithm is employed to obtain the optimum results.

\section{Algorithm 2.}

Step 1 . Set $m=1$ and input all parametric values.

Step 2. For each $L_{i}, i=1,2, \ldots, n$, perform Steps $2(\mathrm{a})-2(\mathrm{f})$.

Step 2(a). Set $A_{s i 1}=0, \theta_{s i 1}=0$, and $k_{i 1}=0$ (implies $\left.\psi\left(k_{i 1}\right)=0.39894\right)$.

Step 2(b). Substitute $\psi\left(k_{i 1}\right)$ into (15) and evaluate $Q_{i 1}$.

Step 2(c). Utilize $Q_{i 1}$ to calculate the value of $\Phi\left(k_{i 2}\right)$ from (16).

Step 2(d). For the value of $\Phi\left(k_{i 2}\right)$, find $k_{i 2}$ from the normal table and hence evaluate $\psi\left(k_{i 2}\right)$.

Step 2(e). Utilize $Q_{i 1}$ to obtain $\theta_{s i 2}$ and $A_{s i 2}$ from (17) and (18).

Step 2(f). Repeat 2(b)-2(e) until no changes occur in the values of $Q_{i}, k_{i}, \theta_{s i}$, and $A_{s i}$; denote these values by $\left(\widehat{Q_{i}}, \widehat{k_{i}}, \widehat{\theta_{i}}, \widehat{A_{s i}}\right)$.

Step 3. Compare $\widehat{\theta_{s i}}$ and $\theta_{0}$ and $\widehat{A_{s i}}$ and $A_{s 0}$, respectively.

Step 3(a). If $\widehat{\theta_{i}}<\theta_{0}$ and $\widehat{A_{s i}}<A_{s 0}$, then the solution found in Step 1 is optimal for the given $L_{i}$. We denote the optimal solution by $\left(Q_{i}^{*}, k_{i}^{*}, \theta_{i}^{*}, A_{s i}^{*}\right)$; that is, if $\left(Q_{i}^{*}, k_{i}^{*}, \theta_{i}^{*}, A_{s i}^{*}\right)=\left(\widehat{Q_{i}}, \widehat{k_{i}}, \widehat{\theta_{i}}, \widehat{A_{s i}}\right)$, go to Step 4 .

Step 3(b). If $\widehat{\theta_{i}} \geq \theta_{0}$ and $\widehat{A_{s i}}<A_{s 0}$, then for given $L_{i}$, assume $\theta_{i}^{*}=\theta_{0}$ and utilize (15) (replace $\theta$ by $\theta_{0}$ ), (16), and (18) to obtain the new $\left(\widehat{Q_{i}}, \widehat{k_{i}}, \widehat{A_{s i}}\right)$ by similar procedure like Step 1 (the solution is denoted by $\left.\left(\widetilde{Q_{i}}, \widetilde{k_{i}}, \widetilde{A_{s i}}\right)\right)$. If $\widetilde{A_{s i}}<A_{s 0}$, then the optimal solution is found; that is, if $\left(Q_{i}^{*}, k_{i}^{*}, \theta_{i}^{*}, A_{s i}^{*}\right)=\left(\widetilde{Q_{i}}, \widetilde{k_{i}}, \theta_{0}, \widetilde{A_{s i}}\right)$, go to Step 4; otherwise, go to Step 3.

Step 3(c). If $\widehat{\theta_{i}}<\theta_{0}$ and $\widehat{A_{s i}} \geq A_{s 0}$, then for given $L_{i}$, let $A_{s i}{ }^{*}=A_{s 0}$ and utilize (15) (replace $A_{s}$ by $\left.A_{s 0}\right),(16)$, and (17) to obtain the new $\left(\widehat{Q_{i}}, \widehat{k_{i}}, \widehat{\theta_{i}}\right)$ by similar procedure like Step 1 (the solution is denoted by $\left.\left(\widetilde{Q_{i}}, \widetilde{k_{i}}, \widetilde{\theta_{i}}\right)\right)$. If $\widetilde{\theta_{i}}<\theta_{0}$, then the optimal solution is found; that is, if $\left(Q_{i}^{*}, k_{i}^{*}, \theta_{i}^{*}, A_{s i}^{*}\right)=\left(\widetilde{Q_{i}}, \widetilde{k_{i}}, \widetilde{\theta_{i}}, A_{s i}\right)$, go to Step 4; otherwise, go to Step 3.

Step 3(d). If $\widehat{\theta_{i}} \geq \theta_{0}$ and $\widehat{A_{s i}} \geq A_{s 0}$, go to Step 4 .
Step 4. Find $T C_{s c}\left(Q_{i}^{*}, k_{i}^{*}, \theta_{s i}^{*}, A_{s i}^{*}, L_{i}, m\right)$ and $\min _{i=1,2, \ldots, n} T C_{s c}\left(Q_{i}^{*}\right.$, $\left.k_{i}^{*}, \theta_{s i}^{*}, A_{s i}^{*}, L_{i}, m\right)$.

Step 4(a). If $T C_{s c}\left(Q_{i}^{*}, k_{i}^{*}, \theta_{s i}{ }^{*}, A_{s i}{ }^{*}, L_{i}, m\right)=$ $\min _{i=1,2, \ldots, n} T C_{s c}\left(Q_{i}^{*}, k_{i}^{*}, \theta_{s i}^{*}, A_{s i}^{*}, L_{i}, m\right)$, then $T C_{s c}\left(Q_{i}^{*}\right.$, $\left.k_{i}^{*}, \theta_{s i}^{*}, A_{s i}^{*}, L_{i}, m\right)$ is the optimal solution for fixed $m$.

Step 5. Set $m=m+1$. If $T C_{s c}\left(Q_{m}^{*}, k_{m}^{*}, \theta_{s m}^{*}, A_{s m}^{*}, L_{m}, m\right) \leq$ $T C_{s c}\left(Q_{m-1}^{*}, k_{m-1}^{*}, \theta_{s m-1}^{*}, A_{s m-1}^{*}, L_{m-1}, m-1\right)$, repeat Step 2. Otherwise go to Step 6.

Step 6. Set $T C_{s c}\left(Q_{m}^{*}, k_{m}^{*}, \theta_{s m}^{*}, A_{s m}^{*}, L_{m}, m\right)=T C_{s c}\left(Q_{m-1}^{*}\right.$, $\left.k_{m-1}^{*}, \theta_{s m-1}^{*}, A_{s m-1}^{*}, L_{m-1}, m-1\right)$. Then $\left(Q^{*}, k^{*}, L^{*}, \theta_{s}^{*}\right.$, $\left.A_{s}{ }^{*}, m^{*}\right)$ is the optimal solution and the optimal reorder point can be calculated from $r^{*}=D L^{*}+k^{*} \sigma \sqrt{L^{*}}$, where $r^{*}$ denotes the optimal reorder point.

\section{Numerical Experiments}

The input parameters are taken from Sarkar and Moon [18] and the rest of the values are taken from Sarkar and Majumder [39] (see Tables 3 and 4 for it) as follows:

$$
\begin{aligned}
& D=600 \text { units/year. } \\
& A_{0}=\$ 1500 / \text { setup. } \\
& A_{b}=\$ 200 / \text { order. } \\
& h_{b}=\$ 100 / \text { unit/year. } \\
& h_{s}=\$ 80 / \text { unit/year. } \\
& \pi=\$ 5 / \text { unit. } \\
& \pi_{0}=\$ 10 / \text { unit. } \\
& P=1500 \text { unit/year. } \\
& s=\$ 75 / \text { unit. } \\
& \theta_{0}=0.0002 . \\
& B=5800 . \\
& \alpha=0.5 \text { dollar/unit. } \\
& b=400 . \\
& \sigma=7 \text { units. } \\
& \rho=0.2 \text { dollar/unit. } \\
& t c_{i}=\$ 0.1 / \text { unit. } \\
& p c=\$ 2 / \text { unit. } \\
& N=3 .
\end{aligned}
$$

The optimal cost $T C_{s c}=\$ 1961.21 /$ year, and the optimal decision variable is $Q^{*}=37.11, k^{*}=1.89, \theta^{*}=$ $.000004, A_{s}=\$ 1076.35, m=2, L=21$ days. It is clearly found that the optimum lot size belongs to the maximum range of transportation discount, which indicates that the supply chain is profitable forever for the purpose of transportation discount with the trade-credit financing. 
TABLE 3: Lead time data.

\begin{tabular}{lccc}
\hline $\begin{array}{l}\text { Lead time } \\
\text { component } i\end{array}$ & $\begin{array}{c}\text { Normal duration } \\
T_{i} \text { (days) }\end{array}$ & $\begin{array}{c}\text { Minimum } \\
\text { duration } t_{i} \text { (days) }\end{array}$ & $\begin{array}{c}\text { Unit crashing } \\
\text { cost } c_{i}(\$ / \text { day })\end{array}$ \\
\hline 1 & 20 & 6 & 0.4 \\
2 & 20 & 6 & 1.2 \\
3 & 20 & 9 & 5.0 \\
\hline
\end{tabular}

TABLE 4: Transportation cost structure.

\begin{tabular}{lc}
\hline Range & Unit transportation cost \\
\hline $0 \leq Q<100$ & 0.4 \\
$100 \leq Q<200$ & 0.25 \\
$200 \leq Q<300$ & 0.17 \\
$3000 \leq Q$ & 0.01 \\
\hline
\end{tabular}

TABLE 5: Sensitivity analysis.

\begin{tabular}{ccc}
\hline Parameters & Changes of parameters (in \%) & $T_{s c}$ (in \%) \\
\hline \multirow{4}{*}{$A_{0}$} & $-10 \%$ & -15.58 \\
& $-5 \%$ & -7.58 \\
& $+5 \%$ & 7.21 \\
& $+10 \%$ & 14.09 \\
\hline \multirow{4}{*}{$h_{b}$} & $-10 \%$ & -32.40 \\
& $-5 \%$ & -16.10 \\
& $+5 \%$ & 15.83 \\
& $+10 \%$ & 23.71 \\
$h_{s}$ & $-10 \%$ & -65.91 \\
& $-5 \%$ & -32.15 \\
& $+5 \%$ & 30.70 \\
& $+10 \%$ & 60.07 \\
$A_{b}$ & $-10 \%$ & -7.45 \\
& $-5 \%$ & -3.68 \\
& $+5 \%$ & 3.58 \\
& $+10 \%$ & 7.08 \\
\hline \multirow{4}{*}{$s$} & $-10 \%$ & -16.58 \\
& $-5 \%$ & -16.00 \\
& $+5 \%$ & 15.18 \\
& $+10 \%$ & 14.67 \\
\hline & $-10 \%$ & -1.72 \\
& $-5 \%$ & -8.36 \\
& $+5 \%$ & 7.78 \\
& & 2.12 \\
\hline & &
\end{tabular}

3.1. Sensitivity Analysis. Sensitivity analysis for the total cost of supply chain is executed with changing parameters by $-10 \%,-5 \%,+5 \%$, and $+10 \%$ in (Table 5 ). From the sensitivity analysis results, the following can be concluded:

(i) The holding cost for supplier is the most sensitive cost in the supply chain. Negative changes are more than positive changes; that is, when supplier's holding cost increases total cost increases and vice versa. Its effects are more in supply chain than any other parameters.

(ii) The holing cost of buyer is 2 nd most sensitive comparing other costs of the supply chain. Negative changes are more than positive changes. Decreasing value of

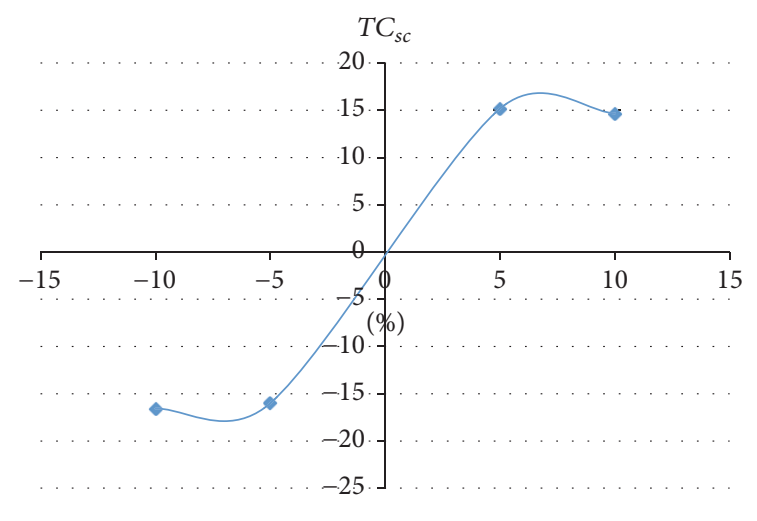

Figure 2: $s$ versus total cost.

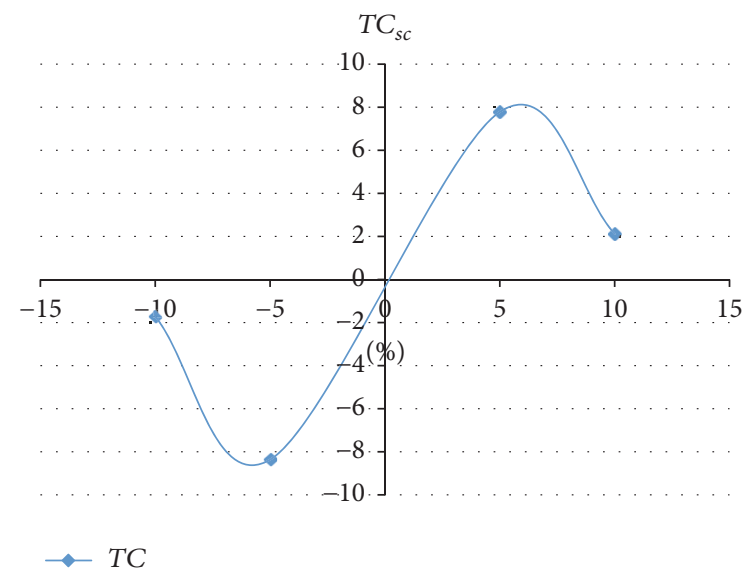

FIGURE 3: $\alpha$ versus total cost.

buyer's holding cost affects more than the increasing value of buyer's holding cost in the total supply chain cost.

(iii) From the sensitivity analysis, it is found that if initial setup cost increases, total cost also increases. It follows that negative and positive changes are almost similar for two changes. Negative changes are slightly more than positive change. Thus, this model considered the reduction of this setup cost by some investment function and by the numerical study, the obtained reduced setup cost with reduced total supply chain cost.

(iv) The increasing value of the buyer's ordering cost indicates the increasing value of the total cost. By comparing the changes within positive and negative direction, two changes are similar. Positive and negative percentage changes are almost same.

(v) If rework cost increases or decreases, then the total cost increases or decreases and negative percentage change and positive percentage change are almost the same (see Figure 2).

(vi) The percentage changes for annual fractional cost are less sensitive than rework cost. Total supply cost 
change increases for the increase of this parameter. This is the least sensitive parameter among all parameters (see Figure 3).

\section{Conclusions}

The paper developed a supply chain model with a stochastic lead time demand, trade-credit policy, quality improvement of products, setup cost reduction of supplier, and variable backorder rate. The backorder rate was lead time-dependent. The aim was to minimize the total supply chain cost with simultaneous optimization of six decision variables as number of shipments, lot size, lead time, setup cost of supplier, quality improvement parameters, and safety stock. Sarkar and Moon [18] did not consider supply chain model and we extended their model with supplier-buyer supply chain model and trade-credit policy. Due to highly nonlinear cost equation, we cannot obtain closed form solutions. We used an improved algorithm to obtain the numerical results. Our results indicated that the cost was minimized based on the existing literature. The limitation of the model was that we used constant demand for both buyer and supplier. The managers can use our suggested policy and can save more funds. This model can be extended with the uncertain demand along with multiechelon sustainable supply chain model. Several sustainability issues like water resources and energy consumption can be added to make a new and improved sustainable supply chain.

\section{Appendix}

Proof of Lemma 1. For given concave function $L \in\left[L_{i}, L_{i-1}\right]$ and $m$ is integer, thus Hessian matrix $H$ is calculated for the variables $Q^{*}, k^{*}, \theta^{*}, A_{s}{ }^{*}$ as follows:

$H$

$$
=\left[\begin{array}{llll}
\frac{\partial^{2} T C_{s c}(\cdot)}{\partial Q^{*}} & \frac{\partial^{2} T C_{s c}(\cdot)}{\partial Q^{*} \partial k^{*}} & \frac{\partial^{2} T C_{s c}(\cdot)}{\partial Q^{*} \partial \theta^{*}} & \frac{\partial^{2} T C_{s c}(\cdot)}{\partial Q^{*} \partial A_{s}{ }^{*}} \\
\frac{\partial^{2} T C_{s c}(\cdot)}{\partial k^{*} \partial Q^{*}} & \frac{\partial^{2} T C_{s c}(\cdot)}{\partial k^{* 2}} & \frac{\partial^{2} T C_{s c}(\cdot)}{\partial k^{*} \partial \theta^{*}} & \frac{\partial^{2} T C_{s c}(\cdot)}{\partial k^{*} \partial A_{s}{ }^{*}} \\
\frac{\partial^{2} T C_{s c}(\cdot)}{\partial \theta^{*} \partial Q^{*}} & \frac{\partial^{2} T C_{s c}(\cdot)}{\partial \theta^{*} \partial k^{*}} & \frac{\partial^{2} T C_{s c}(\cdot)}{\partial \theta^{* 2}} & \frac{\partial^{2} T C_{s c}(\cdot)}{\partial \theta^{*} \partial A_{s}^{*}} \\
\frac{\partial^{2} T C_{s c}(\cdot)}{\partial A_{s}^{*} \partial Q^{*}} & \frac{\partial^{2} T C_{s c}(\cdot)}{\partial A_{s}^{*} \partial k^{*}} & \frac{\partial^{2} T C_{s c}(\cdot)}{\partial A_{s}^{*} \partial \theta^{*}} & \frac{\partial^{2} T C_{s c}(\cdot)}{\partial A_{s}^{* 2}}
\end{array}\right]
$$

where $T C_{s c}(\cdot)=T C_{s c}\left(Q^{*}, k^{*}, \theta^{*}, A_{s}{ }^{*}, m, L\right)$. The partial derivatives with respect to decision variables are obtained as follows:

$$
\begin{aligned}
& \frac{\partial^{2} T C_{s c}\left(Q^{*}, k^{*}, \theta^{*}, A_{s}^{*}, m, L\right)}{\partial Q^{* 2}}=\frac{2}{Q^{* 3}}\left[A_{b} D\right. \\
& +\frac{D \bar{\pi} \xi}{\rho}+D R(L)-\frac{p c i_{b} D^{2} N^{2}}{2}-\frac{p c i_{b} D N^{2} \xi}{2(1+\xi)} \\
& \left.+\frac{p c i_{s} D^{2} N^{2}}{2}+\frac{A_{s} D}{m}\right],
\end{aligned}
$$

$$
\begin{aligned}
& \frac{\partial^{2} T C_{s c}\left(Q^{*}, k^{*}, \theta^{*}, A_{s}{ }^{*}, m, L\right)}{\partial k^{* 2}}=\sigma \sqrt{L} \varphi(k)\left[\frac{h_{b} \xi}{(1+\xi)}\right. \\
& \left.+\frac{D \bar{\pi}}{Q^{*}}\right]+\sigma \sqrt{L} \xi_{3}\left[\frac{h_{b} \rho \sigma \sqrt{L} \xi_{3}}{(1+\xi)}\right. \\
& \left.-\frac{h_{b} \rho^{2} \sigma^{2} L \xi_{3} \psi(k)}{(1+\xi)^{2}}\right] \\
& +\sigma \sqrt{L} \xi_{3}\left[\left(h_{b} \rho \sigma \sqrt{L}+\frac{D \pi_{0} \sigma \rho \sqrt{L}}{Q^{*}}\right)\right. \\
& \left.\cdot\left(\frac{\xi_{3}}{(1+\xi)^{2}}\right)\right]+\sigma \sqrt{L} \psi(k) \\
& \cdot\left[\left(h_{b} \rho \sigma \sqrt{L}+\frac{D \pi_{0} \sigma \rho \sqrt{L}}{Q^{*}}\right)\right. \\
& \left.\cdot\left(\frac{\varphi(k)}{(1+\xi)^{2}}-\frac{2 \rho \sigma \sqrt{L}\left(\xi_{3}\right)^{2}}{(1+\xi)^{2}}\right)\right] \\
& -\frac{D p c N i_{b} \rho \sqrt{L} \varphi(k)}{Q^{*}(1+\xi)^{2}}+\frac{2 D p c N i_{b} \rho^{2} \sigma^{2} L\left(\xi_{3}\right)^{2}}{Q^{*}(1+\xi)^{3}}, \\
& \frac{\partial^{2} T C_{s c}\left(Q^{*}, k^{*}, \theta^{*}, A_{s}^{*}, m, L\right)}{\partial \theta^{* 2}}=\frac{\alpha b}{\theta^{*^{2}}}, \\
& \frac{\partial^{2} T C_{s c}\left(Q^{*}, k^{*}, \theta^{*}, A_{s}{ }^{*}, m, L\right)}{\partial A_{s}{ }^{* 2}}=\frac{\alpha B}{A_{s}{ }^{2}}, \\
& \frac{\partial^{2} T C_{s c}\left(Q^{*}, k^{*}, \theta^{*}, A_{s}^{*}, m, L\right)}{\partial Q^{*} \partial k^{*}} \\
& =\frac{\partial^{2} T C_{s c}\left(Q^{*}, k^{*}, \theta^{*}, A_{s}^{*}, m, L\right)}{\partial k^{*} \partial Q^{*}} \\
& =\frac{1}{\mathrm{Q}^{* 2}}\left[-D \sigma \sqrt{L} \pi \xi_{3}-\frac{2 D \pi_{0} \sigma \sqrt{L} \xi_{3} \xi}{(1+\xi)}\right. \\
& +\frac{D \pi_{0} \sigma \sqrt{L} \xi_{3} \xi^{2}}{(1+\xi)^{2}}+\frac{D N^{2} p c i_{b} \rho \sigma \sqrt{L} \xi_{3}}{2(1+\xi)} \\
& \left.-\frac{D N^{2} p c i_{b} \rho \sigma \sqrt{L} \xi_{3} \xi}{2(1+\xi)^{2}}\right] \text {, } \\
& \frac{\partial^{2} T C_{s c}\left(Q^{*}, k^{*}, \theta^{*}, A_{s}^{*}, m, L\right)}{\partial Q^{*} \partial \theta^{*}} \\
& =\frac{\partial^{2} T C_{s c}\left(Q^{*}, k^{*}, \theta^{*}, A_{s}{ }^{*}, m, L\right)}{\partial \theta^{*} \partial Q^{*}}=\frac{s D m}{2}, \\
& \frac{\partial^{2} T C_{s c}\left(Q^{*}, k^{*}, \theta^{*}, A_{s}{ }^{*}, m, L\right)}{\partial Q^{*} \partial A_{s}{ }^{*}} \\
& =\frac{\partial^{2} T C_{s c}\left(Q^{*}, k^{*}, \theta^{*}, A_{s}{ }^{*}, m, L\right)}{\partial A_{s}{ }^{*} \partial Q^{*}}=-\frac{D}{m Q^{* 2}},
\end{aligned}
$$




$$
\begin{gathered}
\frac{\partial^{2} T C_{s c}\left(Q^{*}, k^{*}, \theta^{*}, A_{s}{ }^{*}, m, L\right)}{\partial k^{*} \partial \theta^{*}} \\
=\frac{\partial^{2} T C_{s c}\left(Q^{*}, k^{*}, \theta^{*}, A_{s}{ }^{*}, m, L\right)}{\partial \theta^{*} \partial k^{*}}=0, \\
\frac{\partial^{2} T C_{s c}\left(Q^{*}, k^{*}, \theta^{*}, A_{s}{ }^{*}, m, L\right)}{\partial k^{*} \partial A_{s}{ }^{*}} \\
=\frac{\partial^{2} T C_{s c}\left(Q^{*}, k^{*}, \theta^{*}, A_{s}{ }^{*}, m, L\right)}{\partial A_{s}{ }^{*} \partial k^{*}}=0, \\
\frac{\partial^{2} T C_{s c}\left(Q^{*}, k^{*}, \theta^{*}, A_{s}{ }^{*}, m, L\right)}{\partial \theta^{*} \partial A_{s}{ }^{*}} \\
=\frac{\partial^{2} T C_{s c}\left(Q^{*}, k^{*}, \theta^{*}, A_{s}{ }^{*}, m, L\right)}{\partial A_{s}{ }^{*} \partial \theta^{*}}=0 .
\end{gathered}
$$

At the optimum values of the decision variables, the principal minors are calculated to confirm their positivity as follows.

For the 1st minor, one can obtain easily as

$$
\begin{aligned}
& \operatorname{det}\left(H_{11}\right)=\operatorname{det}\left(\frac{\partial^{2} T C_{s c}(\cdot)}{\partial Q^{* 2}}\right)=\frac{2}{Q^{* 3}}\left[A_{b} D+\frac{D \bar{\pi} \xi}{\rho}\right. \\
& +D R(L)-\frac{p c i_{b} D^{2} N^{2}}{2}-\frac{p c i_{b} D N^{2} \xi}{2(1+\xi)} \\
& \left.+\frac{p c i_{s} D^{2} N^{2}}{2}+\frac{A_{s} D}{m}\right]>0 .
\end{aligned}
$$

For 2nd minor, it is found as

$$
\begin{aligned}
\operatorname{det}\left(H_{22}\right) & =\operatorname{det}\left[\begin{array}{ll}
\frac{\partial^{2} T C_{s c}(\cdot)}{\partial Q^{* 2}} & \frac{\partial^{2} T C_{s c}(\cdot)}{\partial Q^{*} \partial k^{*}} \\
\frac{\partial^{2} T C_{s c}(\cdot)}{\partial k^{*} \partial Q^{*}} & \frac{\partial^{2} T C_{s c}(\cdot)}{\partial k^{* 2}}
\end{array}\right] \\
& =\omega \tau-v^{2}
\end{aligned}
$$

where

$$
\begin{aligned}
\omega & =\frac{2}{Q^{* 3}}\left[A_{b} D+\frac{D \bar{\pi} \xi}{\rho}+D R(L)-\frac{p c i_{b} D^{2} N^{2}}{2}\right. \\
& \left.-\frac{p c i_{b} D N^{2} \xi}{2(1+\xi)}+\frac{p c i_{s} D^{2} N^{2}}{2}+\frac{A_{s} D}{m}\right], \\
\tau & =\sigma \sqrt{L} \varphi(k)\left[\frac{h_{b} \xi}{(1+\xi)}+\frac{D \bar{\pi}}{Q^{*}}\right] \\
& +\sigma \sqrt{L} \xi_{3}\left[\frac{h_{b} \rho \sigma \sqrt{L} \xi_{3}}{(1+\xi)}-\frac{h_{b} \rho^{2} \sigma^{2} L \xi_{3} \psi(k)}{(1+\xi)^{2}}\right]
\end{aligned}
$$

$$
\begin{aligned}
+ & \sigma \sqrt{L} \xi_{3}\left[\left(h_{b} \rho \sigma \sqrt{L}+\frac{D \pi_{0} \sigma \rho \sqrt{L}}{Q^{*}}\right)\right. \\
& \left.\cdot\left(\frac{\xi_{3}}{(1+\xi)^{2}}\right)\right]+\sigma \sqrt{L} \psi(k) \\
& \cdot\left[\left(h_{b} \rho \sigma \sqrt{L}+\frac{D \pi_{0} \sigma \rho \sqrt{L}}{Q^{*}}\right)\right. \\
& \left.\cdot\left(\frac{\varphi(k)}{(1+\xi)^{2}}-\frac{2 \rho \sigma \sqrt{L}\left(\xi_{3}\right)^{2}}{(1+\xi)^{2}}\right)\right] \\
& -\frac{D p c N i_{b} \rho \sqrt{L} \varphi(k)}{Q^{*}(1+\xi)^{2}}+\frac{2 D p c N i_{b} \rho^{2} \sigma^{2} L\left(\xi_{3}\right)^{2}}{Q^{*}(1+\xi)^{3}} \\
v & =\frac{1}{Q^{* 2}}\left[-D \sigma \sqrt{L} \pi \xi_{3}-\frac{2 D \pi_{0} \sigma \sqrt{L} \xi_{3} \xi}{(1+\xi)}\right. \\
& +\frac{D \pi_{0} \sigma \sqrt{L} \xi_{3} \xi^{2}}{(1+\xi)^{2}}+\frac{D N^{2} p c i_{b} \rho \sigma \sqrt{L} \xi_{3}}{2(1+\xi)} \\
& \left.-\frac{D N^{2} p c i_{b} \rho \sigma \sqrt{L} \xi_{3} \xi}{2(1+\xi)^{2}}\right] \cdot
\end{aligned}
$$

Now,

$$
\begin{aligned}
- & D \sigma \sqrt{L} \pi \xi_{3}-\frac{2 D \pi_{0} \sigma \sqrt{L} \xi_{3} \xi}{(1+\xi)}+\frac{D \pi_{0} \sigma \sqrt{L} \xi_{3} \xi^{2}}{(1+\xi)^{2}} \\
& +\frac{D N^{2} p c i_{b} \rho \sigma \sqrt{L} \xi_{3}}{2(1+\xi)}-\frac{D N^{2} p c i_{b} \rho \sigma \sqrt{L} \xi_{3} \xi}{2(1+\xi)^{2}} \\
& =\frac{2 D \pi_{0} \sigma \sqrt{L} \xi_{3} \xi^{2}-D N^{2} p c i_{b} \rho \sigma \sqrt{L} \xi_{3} \xi}{2(1+\xi)^{2}} \\
& +\frac{D N^{2} p c i_{b} \rho \sigma \sqrt{L} \xi_{3}-4 D \pi_{0} \sigma \sqrt{L} \xi_{3} \xi-2(1+\xi) D \sigma \sqrt{L} \pi \xi_{3}}{2(1+\xi)} .
\end{aligned}
$$

Again

$$
\begin{aligned}
\tau & =\sigma \sqrt{L} \varphi(k)\left[\frac{h_{b} \xi}{(1+\xi)}+\frac{D \bar{\pi}}{Q^{*}}\right]+\sigma \sqrt{L} \xi_{3}\left[\frac{h_{b} \rho \sigma \sqrt{L} \xi_{3}}{(1+\xi)}\right. \\
& \left.-\frac{h_{b} \rho^{2} \sigma^{2} L \xi_{3} \psi(k)}{(1+\xi)^{2}}\right]+\sigma \sqrt{L} \xi_{3}\left[\left(h_{b} \rho \sigma \sqrt{L}+\frac{D \pi_{0} \sigma \rho \sqrt{L}}{Q^{*}}\right)\right.
\end{aligned}
$$$$
\left.\cdot\left(\frac{\xi_{3}}{(1+\xi)^{2}}\right)\right]+\sigma \sqrt{L} \psi(k)\left[\left(h_{b} \rho \sigma \sqrt{L}+\frac{D \pi_{0} \sigma \rho \sqrt{L}}{Q^{*}}\right)\right.
$$$$
\left.\cdot\left(\frac{\varphi(k)}{(1+\xi)^{2}}-\frac{2 \rho \sigma \sqrt{L}\left(\xi_{3}\right)^{2}}{(1+\xi)^{2}}\right)\right]-\frac{D p c N i_{b} \rho \sqrt{L} \varphi(k)}{Q^{*}(1+\xi)^{2}}
$$$$
+\frac{2 D p c N i_{i} \rho^{2} \sigma^{2} L\left(\xi_{3}\right)^{2}}{Q^{*}(1+\xi)^{3}}=\sigma \sqrt{L} \varphi(k)\left[\frac{h_{b} \xi}{(1+\xi)}+\frac{D \bar{\pi}}{Q^{*}}\right]
$$$$
+\sigma \sqrt{L} \xi_{3}\left[\frac{h_{b} \rho \sigma \sqrt{L} \xi_{3}}{(1+\xi)}-\frac{h_{b} \rho^{2} \sigma^{2} L \xi_{3} \psi(k)}{(1+\xi)^{2}}\right]
$$$$
+\frac{2 D p c N i_{b} \rho^{2} \sigma^{2} L\left(\xi_{3}\right)^{2}}{Q^{*}(1+\xi)^{3}}-\frac{D p c N i_{b} \rho \sqrt{L} \varphi(k)}{Q^{*}(1+\xi)^{2}}
$$ 


$$
\begin{aligned}
& +\left[\left(h_{b} \rho \sigma \sqrt{L}+\frac{D \pi_{0} \sigma \rho \sqrt{L}}{Q^{*}}\right)\right. \\
& \left.\cdot\left(\frac{\sigma \sqrt{L}\left(\xi_{3}\right)^{2}+\sigma \sqrt{L} \psi(k) \varphi(k)-2 \rho \sigma \sqrt{L}\left(\xi_{3}\right)^{2} \sigma \sqrt{L} \psi(k)}{(1+\xi)^{2}}\right)\right] \\
& =v^{\prime}+v^{\prime \prime},
\end{aligned}
$$

where

$$
\begin{aligned}
v^{\prime} & =\sigma \sqrt{L} \varphi(k)\left[\frac{h_{b} \xi}{(1+\xi)}+\frac{D \bar{\pi}}{Q^{*}}\right] \\
& +\sigma \sqrt{L} \xi_{3}\left[\frac{h_{b} \rho \sigma \sqrt{L} \xi_{3}}{(1+\xi)}-\frac{h_{b} \rho^{2} \sigma^{2} L \xi_{3} \psi(k)}{(1+\xi)^{2}}\right] \\
& +\frac{2 D p c N i_{b} \rho^{2} \sigma^{2} L\left(\xi_{3}\right)^{2}}{Q^{*}(1+\xi)^{3}}-\frac{D p c N i_{b} \rho \sqrt{L} \varphi(k)}{Q^{*}(1+\xi)^{2}}, \\
v^{\prime \prime} & =\left(h_{b} \rho \sigma \sqrt{L}+\frac{D \pi_{0} \sigma \rho \sqrt{L}}{Q^{*}}\right) \\
& \cdot\left(\frac{\sigma \sqrt{L}\left(\xi_{3}\right)^{2}+\sigma \sqrt{L} \psi(k) \varphi(k)-2 \rho \sigma \sqrt{L}\left(\xi_{3}\right)^{2} \sigma \sqrt{L} \psi(k)}{(1+\xi)^{2}}\right) .
\end{aligned}
$$

Thus, $\omega \tau>v^{2}$ where

$$
\begin{aligned}
\omega= & \frac{2}{Q^{* 3}}\left[A_{b} D+\frac{D \bar{\pi} \xi}{\rho}+D R(L)-\frac{p c i_{b} D^{2} N^{2}}{2}\right. \\
& \left.-\frac{p c i_{b} D N^{2} \xi}{2(1+\xi)}+\frac{p c i_{s} D^{2} N^{2}}{2}+\frac{A_{s} D}{m}\right]>v, \\
\tau & =v^{\prime}+v^{\prime \prime}>v .
\end{aligned}
$$

Hence, $\operatorname{det}\left(H_{22}\right)>0$.

For 3rd minor, the value is obtained as

$$
\begin{aligned}
H_{33} & =\left[\begin{array}{lll}
\frac{\partial^{2} T C_{s c}(\cdot)}{\partial Q^{* 2}} & \frac{\partial^{2} T C_{s c}(\cdot)}{\partial Q^{*} \partial k^{*}} & \frac{\partial^{2} T C_{s c}(\cdot)}{\partial Q^{*} \partial \theta^{*}} \\
\frac{\partial^{2} T C_{s c}(\cdot)}{\partial k^{*} \partial Q^{*}} & \frac{\partial^{2} T C_{s c}(\cdot)}{\partial k^{* 2}} & \frac{\partial^{2} T C_{s c}(\cdot)}{\partial k^{*} \partial \theta^{*}} \\
\frac{\partial^{2} T C_{s c}(\cdot)}{\partial \theta^{*} \partial Q^{*}} & \frac{\partial^{2} T C_{s c}(\cdot)}{\partial \theta^{*} \partial k^{*}} & \frac{\partial^{2} T C_{s c}(\cdot)}{\partial \theta^{* 2}}
\end{array}\right] \\
= & {\left[\begin{array}{ccc}
\omega & v & \frac{s D m}{2} \\
v & \tau & 0 \\
\frac{s D m}{2} & 0 & \frac{\alpha b}{\theta^{* 2}}
\end{array}\right] } \\
= & \frac{s D m}{2}\left[-\frac{s D m}{2} \tau\right]+\frac{\alpha b}{\theta^{* 2}} H_{22} \\
= & \tau\left(\frac{\alpha b}{\theta^{* 2}} \omega-\frac{s^{2} D^{2} m^{2}}{4}\right)-\frac{\alpha b}{\theta^{* 2}} v^{2} .
\end{aligned}
$$

It is already proved that $\tau>v$; thus it is enough to show $\left(\alpha b / \theta^{* 2}\right) \omega-s^{2} D^{2} m^{2} / 4>\left(\alpha b / \theta^{* 2}\right) v$; that is,

$$
\begin{aligned}
\frac{\alpha b}{\theta^{* 2}} \omega-\frac{\alpha b}{\theta^{* 2}} v & >\frac{s^{2} D^{2} m^{2}}{4} \Longrightarrow \\
\frac{\alpha b}{\theta^{* 2}}(\omega-v) & >\frac{s^{2} D^{2} m^{2}}{4} \Longrightarrow \\
\omega-v & >\frac{s^{2} D^{2} m^{2} \theta^{* 2}}{4 \alpha b} \Longrightarrow \\
\omega-v-\frac{s^{2} D^{2} m^{2} \theta^{* 2}}{4 \alpha b} & >0 ;
\end{aligned}
$$

that is, $\operatorname{det}\left(H_{33}\right)>0$.

Finally, for 4th minor, the optimum value is obtained as

$H_{44}$

$$
=\left[\begin{array}{cccc}
\frac{\partial^{2} T C_{s c}(\cdot)}{\partial Q^{* 2}} & \frac{\partial^{2} T C_{s c}(\cdot)}{\partial Q^{*} \partial k^{*}} & \frac{\partial^{2} T C_{s c}(\cdot)}{\partial Q^{*} \partial \theta^{*}} & \frac{\partial^{2} T C_{s c}(\cdot)}{\partial Q^{*} \partial A_{s}{ }^{*}} \\
\frac{\partial^{2} T C_{s c}(\cdot)}{\partial k^{*} \partial Q^{*}} & \frac{\partial^{2} T C_{s c}(\cdot)}{\partial k^{* 2}} & \frac{\partial^{2} T C_{s c}(\cdot)}{\partial k^{*} \partial \theta^{*}} & \frac{\partial^{2} T C_{s c}(\cdot)}{\partial k^{*} \partial A_{s}{ }^{*}} \\
\frac{\partial^{2} T C_{s c}(\cdot)}{\partial \theta^{*} \partial Q^{*}} & \frac{\partial^{2} T C_{s c}(\cdot)}{\partial \theta^{*} \partial k^{*}} & \frac{\partial^{2} T C_{s c}(\cdot)}{\partial \theta^{* 2}} & \frac{\partial^{2} T C_{s c}(\cdot)}{\partial \theta^{*} \partial A_{s}{ }^{*}} \\
\frac{\partial^{2} T C_{s c}(\cdot)}{\partial A_{s}{ }^{*} \partial Q^{*}} & \frac{\partial^{2} T C_{s c}(\cdot)}{\partial A_{s}^{*} \partial k^{*}} & \frac{\partial^{2} T C_{s c}(\cdot)}{\partial A_{s}^{*} \partial \theta^{*}} & \frac{\partial^{2} T C_{s c}(\cdot)}{\partial A_{s}^{* 2}}
\end{array}\right]
$$$$
=-\frac{\partial^{2} T C_{s c}(\cdot)}{\partial Q^{*} \partial A_{s}{ }^{*}}\left[\begin{array}{llll}
\frac{\partial^{2} T C_{s c}(\cdot)}{\partial k^{*} \partial Q^{*}} & \frac{\partial^{2} T C_{s c}(\cdot)}{\partial k^{* 2}} & \frac{\partial^{2} T C_{s c}(\cdot)}{\partial k^{*} \partial \theta^{*}} \\
\frac{\partial^{2} T C_{s c}(\cdot)}{\partial \theta^{*} \partial Q^{*}} & \frac{\partial^{2} T C_{s c}(\cdot)}{\partial \theta^{*} \partial k^{*}} & \frac{\partial^{2} T C_{s c}(\cdot)}{\partial \theta^{* 2}} \\
\frac{\partial^{2} T C_{s c}(\cdot)}{\partial A_{s}{ }^{*} \partial Q^{*}} & \frac{\partial^{2} T C_{s c}(\cdot)}{\partial A_{s}{ }^{*} \partial k^{*}} & \frac{\partial^{2} T C_{s c}(\cdot)}{\partial A_{s}{ }^{*} \partial \theta^{*}}
\end{array}\right]
$$

$$
\begin{aligned}
& +\frac{\partial^{2} T C_{s c}(\cdot)}{\partial A_{s}{ }^{2}} H_{33} \\
& =\frac{D}{m Q^{* 2}}\left[\begin{array}{ccc}
v & \tau & 0 \\
\frac{s D m}{2} & 0 & \frac{\alpha b}{\theta^{* 2}} \\
-\frac{D}{m Q^{* 2}} & 0 & 0
\end{array}\right]+\frac{\alpha B}{A_{s}^{* 2}} H_{33} \\
& =\frac{\alpha b D^{2} \tau}{m^{2} Q^{* 4} \theta^{* 2}}+\frac{\alpha B}{A_{s}{ }^{* 2}} H_{33} .
\end{aligned}
$$

First part is positive and $H_{33}$ is already shown greater than zero.

Hence, $\operatorname{det}\left(H_{44}\right)>0$.

From the above calculations, all principal minors of the Hessian matrix are positive. Therefore, the Hessian matrix $H$ is positively definite at $\left(Q^{*}, k^{*}, \theta^{*}, A_{s}{ }^{*}\right)$. Thus, total cost function has a global minimum.

\section{Conflicts of Interest}

The authors declare that there are no conflicts of interest regarding the publication of this paper. 


\section{References}

[1] R. Uthayakumar and S. Priyan, "Permissible delay in payments in the two-echelon inventory system with controllable setup cost and lead time under service level constraint," International Journal of Information and Management Sciences, vol. 24, no. 3, pp. 193-211, 2013.

[2] E. L. Porteus, "Investing in reduced setups in the EOQ model," Management Science, vol. 31, no. 8, pp. 998-1010, 1985.

[3] L.-Y. Ouyang, C.-K. Chen, and H.-C. Chang, "Lead time and ordering cost reductions in continuous review inventory systems with partial backorders," Journal of the Operational Research Society, vol. 50, no. 12, pp. 1272-1279, 1999.

[4] Y. Y. Woo, S.-L. Hsu, and S. Wu, "An integrated inventory model for a single vendor and multiple buyers with ordering cost reduction," International Journal of Production Economics, vol. 73, no. 3, pp. 203-215, 2001.

[5] H.-C. Chang, L.-Y. Ouyang, K.-S. Wu, and C.-H. Ho, "Integrated vendor-buyer cooperative inventory models with controllable lead time and ordering cost reduction," European Journal of Operational Research, vol. 170, no. 2, pp. 481-495, 2006.

[6] T. Zhang, L. Liang, Y. Yu, and Y. Yu, "An integrated vendormanaged inventory model for a two-echelon system with order cost reduction," International Journal of Production Economics, vol. 109, no. 1-2, pp. 241-253, 2007.

[7] D. Shin, R. Guchhait, B. Sarkar, and M. Mittal, "Controllable lead time, service level constraint, and transportation discounts in a continuous review inventory model," RAIRO Operations Research, vol. 50, no. 4-5, pp. 921-934, 2016.

[8] C.-K. Huang, "An integrated inventory model under conditions of order processing cost reduction and permissible delay in payments," Applied Mathematical Modelling, vol. 34, no. 5, pp. 1352-1359, 2010.

[9] B. Sarkar, "An EOQ model with delay in payments and stock dependent demand in the presence of imperfect production," Applied Mathematics and Computation, vol. 218, no. 17, pp. 8295-8308, 2012.

[10] R. Ganeshan, "Managing supply chain inventories: a multiple retailer, one warehouse, multiple supplier model," International Journal of Production Economics, vol. 59, no. 1, pp. 341-354, 1999.

[11] B. Sarkar, S. Saren, D. Sinha, and S. Hur, "Effect of unequal lot sizes, variable setup cost, and carbon emission cost in a supply chain model," Mathematical Problems in Engineering, vol. 2015, Article ID 469486, 13 pages, 2015.

[12] B. Sarkar, B. Ganguly, M. Sarkar, and S. Pareek, "Effect of variable transportation and carbon emission in a three-echelon supply chain model," Transportation Research Part E: Logistics and Transportation Review, vol. 91, pp. 112-128, 2016.

[13] G. P. Kiesmüller, A. G. de Kok, and J. C. Fransoo, "Transportation mode selection with positive manufacturing lead time," Transportation Research Part E: Logistics and Transportation Review, vol. 41, no. 6, pp. 511-530, 2005.

[14] K. Ertogral, M. Darwish, and M. Ben-Daya, "Production and shipment lot sizing in a vendor-buyer supply chain with transportation cost," European Journal of Operational Research, vol. 176, no. 3, pp. 1592-1606, 2007.

[15] J.-H. Kang and Y.-D. Kim, "Coordination of inventory and transportation managements in a two-level supply chain," International Journal of Production Economics, vol. 123, no. 1, pp. 137-145, 2010.
[16] K.-J. Chung, "The integrated inventory model with the transportation cost and two-level trade credit in supply chain management," Computers \&; Mathematics with Applications, vol. 64, no. 6, pp. 2011-2033, 2012.

[17] L.-Y. Ouyang, C.-K. Chen, and H.-C. Chang, "Quality improvement, setup cost and lead-time reductions in lot size reorder point models with an imperfect production process," Computers and Operations Research, vol. 29, no. 12, pp. 1701-1717, 2002.

[18] B. Sarkar and I. Moon, "Improved quality, setup cost reduction, and variable backorder costs in an imperfect production process," International Journal of Production Economics, vol. 155, pp. 204-213, 2014.

[19] S. H. Yoo, D. Kim, and M.-S. Park, "Lot sizing and quality investment with quality cost analyses for imperfect production and inspection processes with commercial return," International Journal of Production Economics, vol. 140, no. 2, pp. 922-933, 2012.

[20] S. K. Goyal, "Economic order quantity under conditions of permissible delay in payments," Journal of the Operational Research Society, vol. 36, no. 4, pp. 335-338, 1985.

[21] S. P. Aggarwal and C. K. Jaggi, "Ordering policies of deteriorating items under permissible delay in payments," Journal of the Operational Research Society, vol. 46, no. 5, pp. 658-662, 1995.

[22] A. M. M. Jamal, B. R. Sarker, and S. Wang, "An ordering policy for deteriorating items with allowable shortage and permissible delay in payment," Journal of the Operational Research Society, vol. 48, no. 8, pp. 826-833, 1997.

[23] J.-T. Teng, "On the economic order quantity under conditions of permissible delay in payments," Journal of the Operational Research Society, vol. 53, no. 8, pp. 915-918, 2002.

[24] H.-C. Chang, "A note on permissible delay in payments for (Q, $\mathrm{R}$ ) inventory systems with ordering cost reduction," International Journal of Information and Management Sciences, vol. 13, no. 4, pp. 1-11, 2002.

[25] M. Y. Jaber and I. H. Osman, "Coordinating a two-level supply chain with delay in payments and profit sharing," Computers and Industrial Engineering, vol. 50, no. 4, pp. 385-400, 2006.

[26] J. Luo, "Buyer-vendor inventory coordination with credit period incentives," International Journal of Production Economics, vol. 108, no. 1-2, pp. 143-152, 2007.

[27] B. Sarkar, H. Gupta, K. Chaudhuri, and S. K. Goyal, "An integrated inventory model with variable lead time, defective units and delay in payments," Applied Mathematics and Computation, vol. 237, pp. 650-658, 2014.

[28] B. Sarkar, "Supply chain coordination with variable backorder, inspections, and discount policy for fixed lifetime products," Mathematical Problems in Engineering, vol. 2016, Article ID 6318737, 14 pages, 2016.

[29] K. V. Geetha and R. Uthayakumar, "Economic design of an inventory policy for non-instantaneous deteriorating items under permissible delay in payments," Journal of Computational and Applied Mathematics, vol. 233, no. 10, pp. 2492-2505, 2010.

[30] J. C. Pan, M.-C. Lo, and Y.-C. Hsiao, "Optimal reorder point inventory models with variable lead time and backorder discount considerations," European Journal of Operational Research, vol. 158, no. 2, pp. 488-505, 2004.

[31] J. C.-H. Pan and Y.-C. Hsiao, "Integrated inventory models with controllable lead time and backorder discount considerations," International Journal of Production Economics, vol. 93-94, pp. 387-397, 2005. 
[32] W.-C. Lee, J.-W. Wu, and C.-L. Lei, "Computational algorithmic procedure for optimal inventory policy involving ordering cost reduction and back-order discounts when lead time demand is controllable," Applied Mathematics and Computation, vol. 189, no. 1, pp. 186-200, 2007.

[33] M.-C. Lo, J. C.-H. Pan, K.-C. Lin, and J.-W. Hsu, "Impact of lead time and safety factor in mixed inventory models with backorder discounts," Journal of Applied Sciences, vol. 8, no. 3, pp. 528-533, 2008.

[34] Y.-J. Lin, "An integrated vendor-buyer inventory model with backorder price discount and effective investment to reduce ordering cost," Computers and Industrial Engineering, vol. 56, no. 4, pp. 1597-1606, 2009.

[35] L.-Y. Ouyang, N.-C. Yeh, and K.-S. Wu, "Mixture inventory model with backorders and lost sales for variable lead time," Journal of the Operational Research Society, vol. 47, no. 6, pp. 829-832, 1996.

[36] A. Arkan and S. R. Hejazi, "Coordinating orders in a two echelon supply chain with controllable lead time and ordering cost using the credit period," Computers and Industrial Engineering, vol. 62, no. 1, pp. 56-69, 2012.

[37] E. L. Porteus, "Optimal lot sizing, process quality improvement and setup cost reduction," Operations Research, vol. 34, no. 1, pp. 137-144, 1986.

[38] L.-Y. Ouyang, K.-S. Wu, and C.-H. Ho, "An integrated vendorbuyer inventory model with quality improvement and lead time reduction," International Journal of Production Economics, vol. 108, no. 1-2, pp. 349-358, 2007.

[39] B. Sarkar and A. Majumder, "Integrated vendor-buyer supply chain model with vendor's setup cost reduction," Applied Mathematics and Computation, vol. 224, pp. 362-371, 2013. 


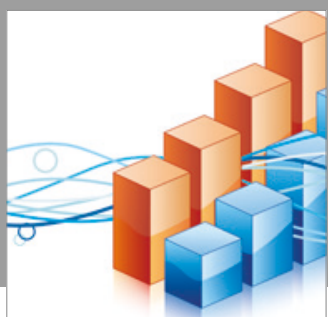

Advances in

Operations Research

vatersals

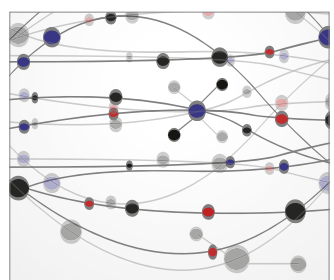

\section{The Scientific} World Journal
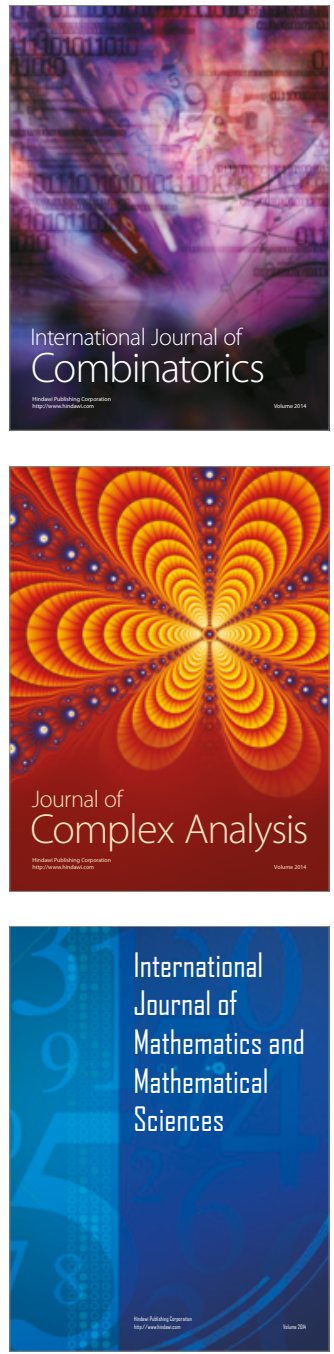
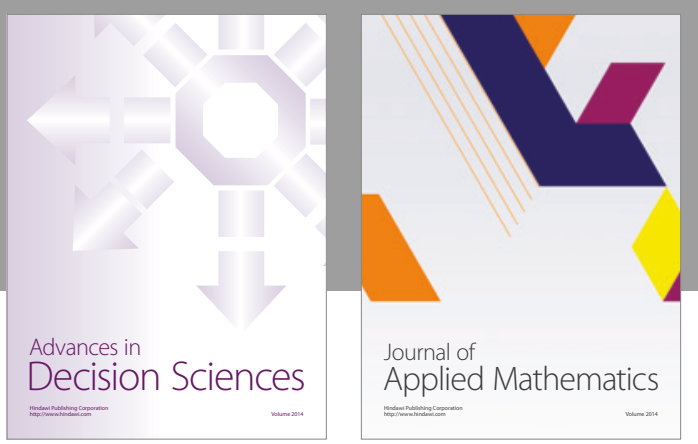

Algebra

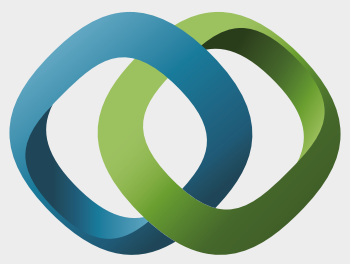

\section{Hindawi}

Submit your manuscripts at

https://www.hindawi.com
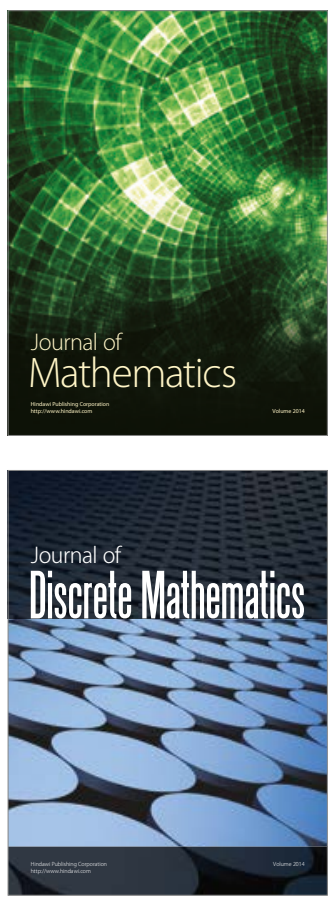

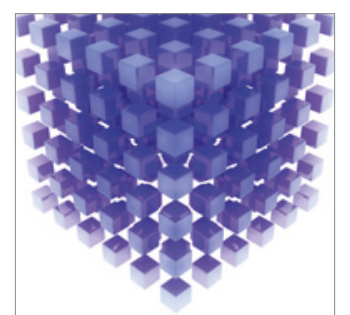

Mathematical Problems in Engineering
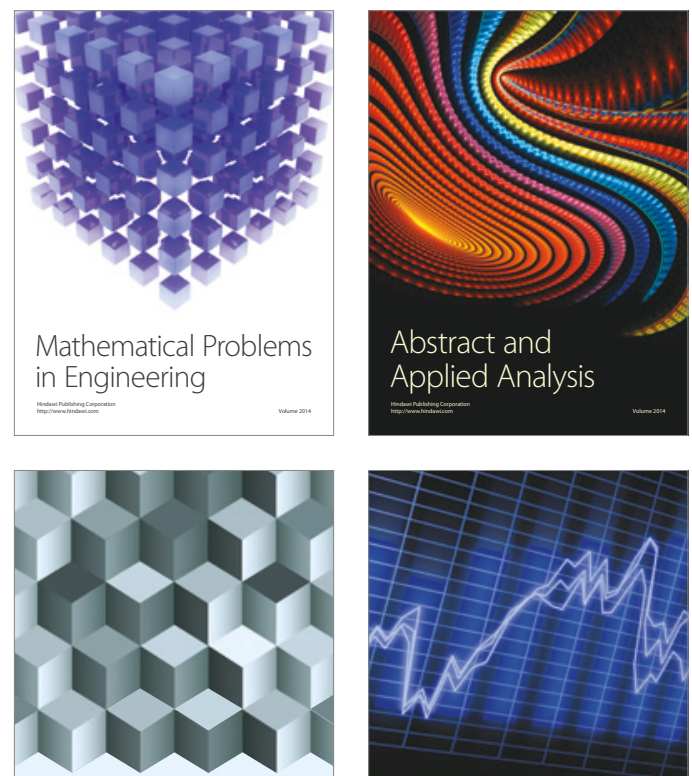

Journal of

Function Spaces

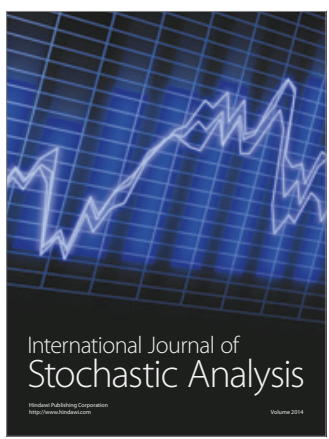

Probability and Statistics
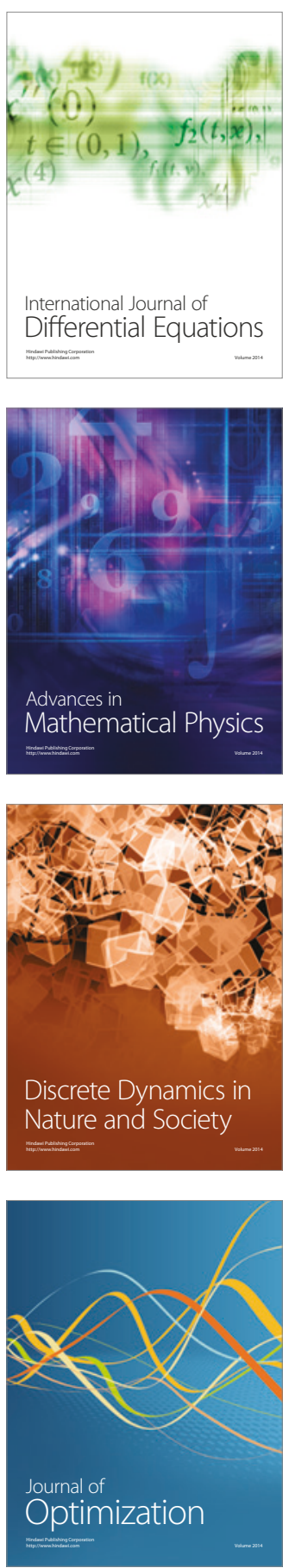